\title{
Erratum to: Contemporary Perspectives on Ageism
}

\author{
Liat Ayalon and Clemens Tesch-Römer
}

\section{Erratum to:}

\section{Ayalon, C. Tesch-Römer (eds.), Contemporary Perspectives on Ageism, International Perspectives on Aging 19, https://doi.org/10.1007/978-3-319-73820-8}

The original version of the book front matter was revised. The following acknowledgement has been added to the copyright page of this book.
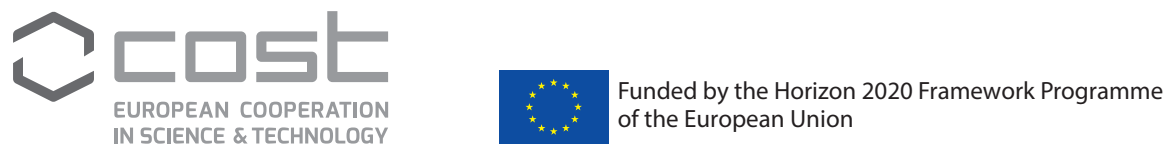

This publication is based upon work from COST Action IS1402, supported by COST (European Cooperation in Science and Technology).

COST is a funding agency for research and innovation networks. Our Actions help connect research initiatives across Europe and enable scientists to grow their ideas by sharing them with their peers. This boosts their research, career and innovation. www.cost.eu

The updated online version of the book can be found at https://doi.org/10.1007/978-3-319-73820-8 